Bull. Mater. Sci., Vol. 22, No. 4, June 1999, pp. 801-804. (C) Indian Academy of Sciences.

\title{
Effect of addition of polycarbonate on sheared flow of red mud-filled isotactic polypropylene
}

\author{
NAVIN CHAND* and S A R HASHMI \\ Regional Research Laboratory, Near Habibganj Naka, Bhopal 462 026, India \\ MS received 11 February 1997; revised 12 March 1999
}

\begin{abstract}
Different volume fractions of polycarbonate (PC) were incorporated to improve thermal stability of red mud (RM) filled polypropylene (PP). Effects of PC addition in RM filled PP on shear stress, melt viscosity, and melt elasticity have been determined under different shear rates by using a capillary rheometer. With the increase in shear rate, addition of PC in RM-filled PP reduced its shear stress and melt viscosity. However, recoverable shear strain increased with $\mathbf{P C}$ content in the blend.
\end{abstract}

Keywords. Filled polymers; red mud; rheology.

\section{Introduction}

Impact strength, stiffness and heat distortion temperature of isotactic polypropylene (PP) are inferior as compared to most engineering plastics. These properties can be modified by the incorporation of various types of particulate fillers (Nielsen 1974). Calcium carbonate was added to thermoplastics to improve their modulus, heat stability (Suetsuga 1982), and dimensional stability (Tanaka and White 1980). Similarly, several other fillers such as talc (Kitano et al 1980), carbon black (Tanaka and White 1980), glass beads (Lepez et al 1990), mica (Xavier et al 1990) and red mud (Chand and Hashmi 1995) have been reported to improve the properties of thermoplastic polymers.

Polycarbonate (PC) is an engineering plastic having outstanding mechanical strength and temperature resistance. Heat distortion temperature of $P C$ at $1820 \mathrm{KPa}$ is reported to be around $140^{\circ} \mathrm{C}$. It is expected that addition of PC in PP can improve its heat resistance and hence upgrade its performance such as endurance of the material at elevated temperatures. Heat deflection temperature (HDT) has been reported to increase with increase of PC content in PP (Liang and Williams 1991). Dimensional stability, HDT, modulus of polymers and polyblends are further improved by the incorporation of particulates. A few recent studies on red mud particulate-filled polymers and polyblends are reported in literature (Chand et al 1996). Mechanical properties of red mud-filled polymers and blends were found to improve by dispersion of red mud particles (Chand and Hashmi 1995; Hashmi and Chand 1996). Naturally, particle size of the dispersant (red mud) influenced the properties of red mud-filled

\footnotetext{
*Author for correspondence
}

polystyrene/low density polyethylene blends. An increase in fineness of particles increased their modulus and tensile strengths (Chand et al 1996). Properties of red mudfilled polypropylene is expected to improve by the addition of PC.

In the present study, different volume fractions of polycarbonate were added to RM-filled polypropylene to investigate the effect of addition of polycarbonate on thermal stability and rheological properties of red mudfilled PP.

\section{Experimental}

Isotactic polypropylene (Koylene M0030) possessing a density of $0.908 \mathrm{~g} / \mathrm{cm}^{3}$ used in this study was supplied by IPCL, India. Commercial grade polycarbonate (Makrolon AL 2643 of Bayer, Germany), was supplied by $M / s$ Ennkay Polymers, Bhopal, India, which was used in these investigations.

Red mud (RM) particles of size $<45 \mu \mathrm{m}$ were separated by wet sieving of RM supplied by BALCO, India. Major chemical constituents of $\mathrm{RM}$ particles are $\mathrm{Fe}_{2} \mathrm{O}_{3}$ (35.85\%), $\mathrm{Al}_{2} \mathrm{O}_{3}(18.34 \%), \mathrm{SiO}_{2}(8.80 \%), \mathrm{TiO}_{2}(12.96 \%)$, $\mathrm{Na}_{2} \mathrm{O}(4.75 \%), \mathrm{CaO}(4 \cdot 15 \%)$, and LOI (14.85\%). Atomic absorption spectrophotometer 902GBC was used to determine $\mathrm{Fe}_{2} \mathrm{O}_{3}, \mathrm{Na}_{2} \mathrm{O}, \mathrm{CaO}$ whereas $\mathrm{SiO}_{2}, \mathrm{TiO}_{2}, \mathrm{Al}_{2} \mathrm{O}_{3}$ were determined by wet chemical analysis method.

PC, PP and RM particles were kept in an air circulating oven at $100^{\circ} \mathrm{C}$ for $24 \mathrm{~h}$ for drying. They were mixed in a $20 \mathrm{~mm}$ single screw extruder having L/D ratio as 27.5 . Temperatures of feed, compressive, metering zones and of the die was fixed at $235,245,250$ and $250^{\circ} \mathrm{C}$, respectively, and screw speed kept constant at $15 \mathrm{rpm}$. Continuous strands obtained from extruder were granulated to a size of $5 \mathrm{~mm}$ length. Whereas RM loading in these 
composites was fixed at $5 \mathrm{wt} \%$ of polymer, weight of PC in PP was varied as 10,20, and $40 \%$.

Thermal characterization of polymer composites were carried out on Stanton Thermal Analysing system. Thermogravimetric analysis (TGA) was carried out under atmospheric conditions because these composites are supposed to prove their performance under these conditions. The heating rate of samples was fixed at $5^{\circ} \mathrm{C}$ per min.

Melt rheological measurements were carried out by using a MCR capillary rheometer. L/D ratio of capillary used was 33.33 and its diameter was $1.5 \mathrm{~mm}$. Measurements were made at a constant temperature of $245^{\circ} \mathrm{C}$ in the range of shear rate $1-10^{3} \mathrm{~s}^{-1}$. Apparent shear rates $\left(\dot{\gamma}_{\mathrm{a}}\right)$ were calculated by using the following equation:

$$
\left(\dot{\gamma}_{\mathrm{a}}\right)=4 \dot{V} / \pi R^{3}
$$

where $\dot{V}$ is volumetric flow rate and $R$ the radius of capillary die. Robinowitsch correction (Han 1976) was applied for determining true shear rate $\left(\dot{\gamma}_{\omega}\right)$. Shear stress $\left(\tau_{\omega}\right)$ at capillary wall was determined by the following equation:

$$
\tau_{\omega}=\Delta P R / 2 L
$$

where $\Delta P$ is a pressure drop along the die and $L$ the length of capillary.

Melt viscosity $(\eta)$, and recoverable shear strain $\left(S_{\mathrm{R}}\right)$ were calculated by the procedures described elsewhere (Han 1976; Gleissle 1982) by the following relationships:

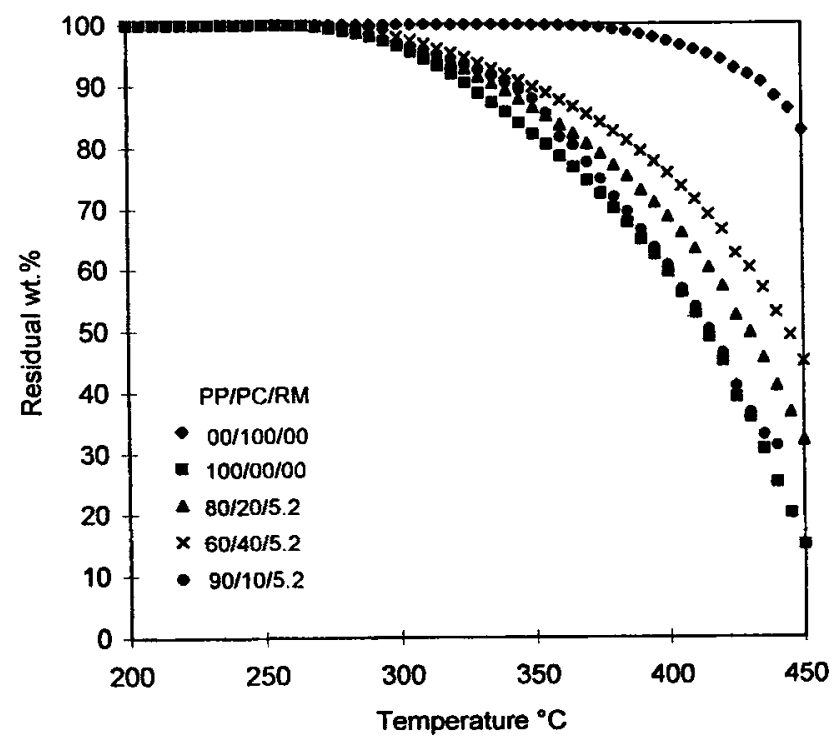

Figure 1. Effect of temperature on weight change (TGA plot) at 5.2 phr loading of BALCO red mud. Note: phr is parts per hundred gram of resin (polymer).

$$
\begin{aligned}
& \eta=\tau_{\omega} / \dot{\gamma}_{\omega}, \\
& S_{\mathrm{R}}=\left(\tau_{11}-\tau_{22}\right) / 2 \tau_{\omega},
\end{aligned}
$$

where $\left(\tau_{11}-\tau_{22}\right)$ is first normal stress difference.

Scanning electron microscope JEOL 35 CF (Philips make) was used to examine the fractured surfaces of the composites.

\section{Results and discussion}

Figure 1 shows different TGA curves for PP, PP/PC/ RM composite, and PC. Thermally most stable polymer among the three systems is PC whereas PP is comparatively less stable than PC. The $90 \mathrm{PP}+10 \mathrm{PC}$ +5.2 RM composite is more stable than pure PP but less stable than PC. Both the said polymers show single stage degradation. In case of blend of PP/PC the TGA curve shifts towards PC on addition of PC in PP. Red mud remained nonreactive and unaffected within the temperature range studied.

Flow curves shown in figure 2 are plots between $\log$ shear stress vs log shear rate for PP/PC/RM for different compositions. Among these compositions, loading of RM was constant at $5 \mathrm{phr}$, however, blend composition was altered. It was observed that addition of PC reduced the shear stress. Minimum shear stress was obtained at $40 \mathrm{wt} \%$ loading of PC. The pseudoplasticity index (slope of the curve) increased with the

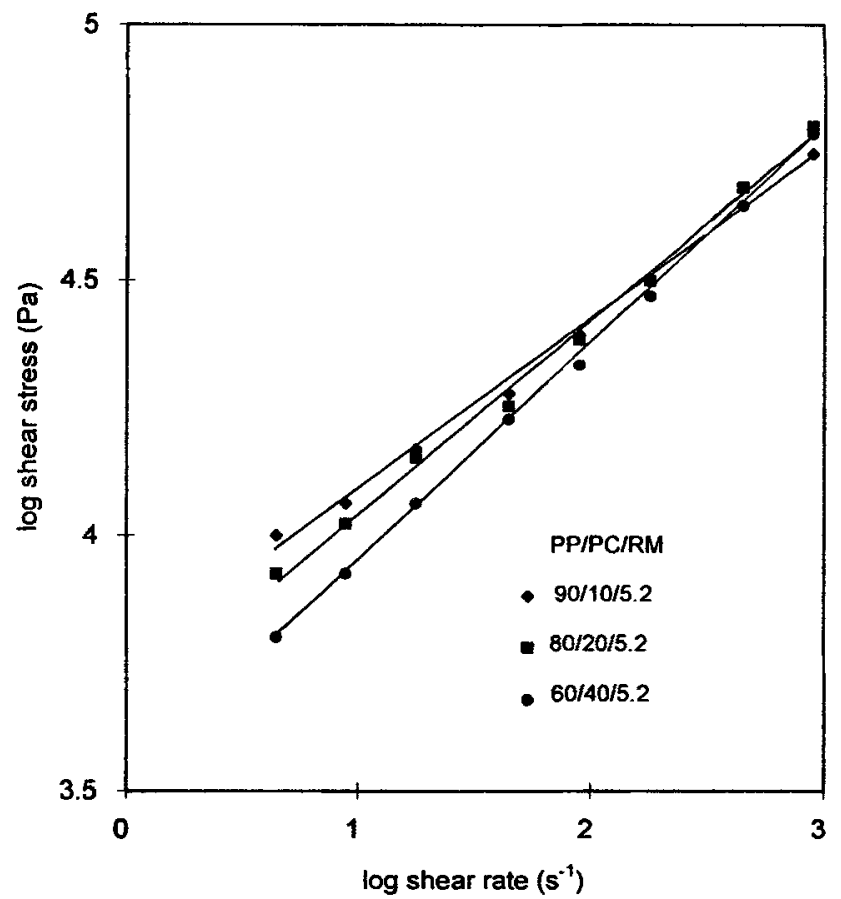

Figure 2. Effect of shear stress on shear rate at $5 \cdot 2$ phr loading of RM particles. 
addition of PC in these blend composites. At any fixed low shear rate, the difference between shear stresses is seen to be higher.

PP and PC are incompatible and immiscible polymers. There is a large disparity reported in the literature (Bartlett et al 1981) in the flow characteristics of PP and PC. In the present study (figure 1) temperature was constant and shear rate was varied and hence morphology of the melt is considered mainly responsible for the observed variation in the flow behaviour of the composites.

Melt viscosity of the system was observed to decrease with the increase in shear rate (figure 3 ) as well as PC content. These observations are in agreement with those of Dobresu and Cobzaru (1978) and Utracki (1984), which was attributed to lubricating effect of polymeric components. Moreover it may be due to the deformation of the dispersed phase (PC) droplets during flow under applied shear stress. The dispersed droplets get elongated and aligned in the direction of flow thus facilitating the flow. As is evident from figure 4 droplet size increased with PC content. Large droplets are easier to deform and hence promote ease of flow at higher PC content.

Cryogenically fractured surfaces of PP/PC/RM at constant RM loading of 5 phr at different blend compositions are shown in figure 4. Spherical domains of PC are seen to be embedded in the PP matrix. Average size of these domains at composition $80 / 70 / 5 \cdot 26$ (PP/PC/RM) is estimated to be less than $20 \mu \mathrm{m}$. On increasing the PC content (figure $4 \mathrm{~b}$ ), the size of domains increased up to

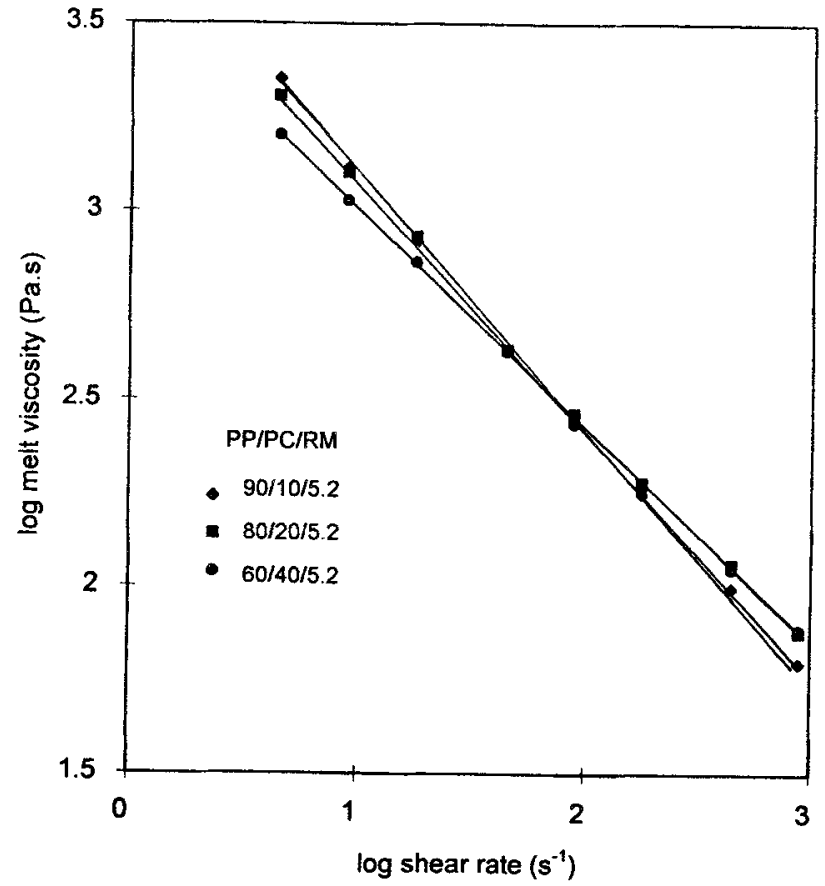

Figure 3. Variation of melt viscosity with shear rate at $5.2 \mathrm{phr}$ loading of RM particles.
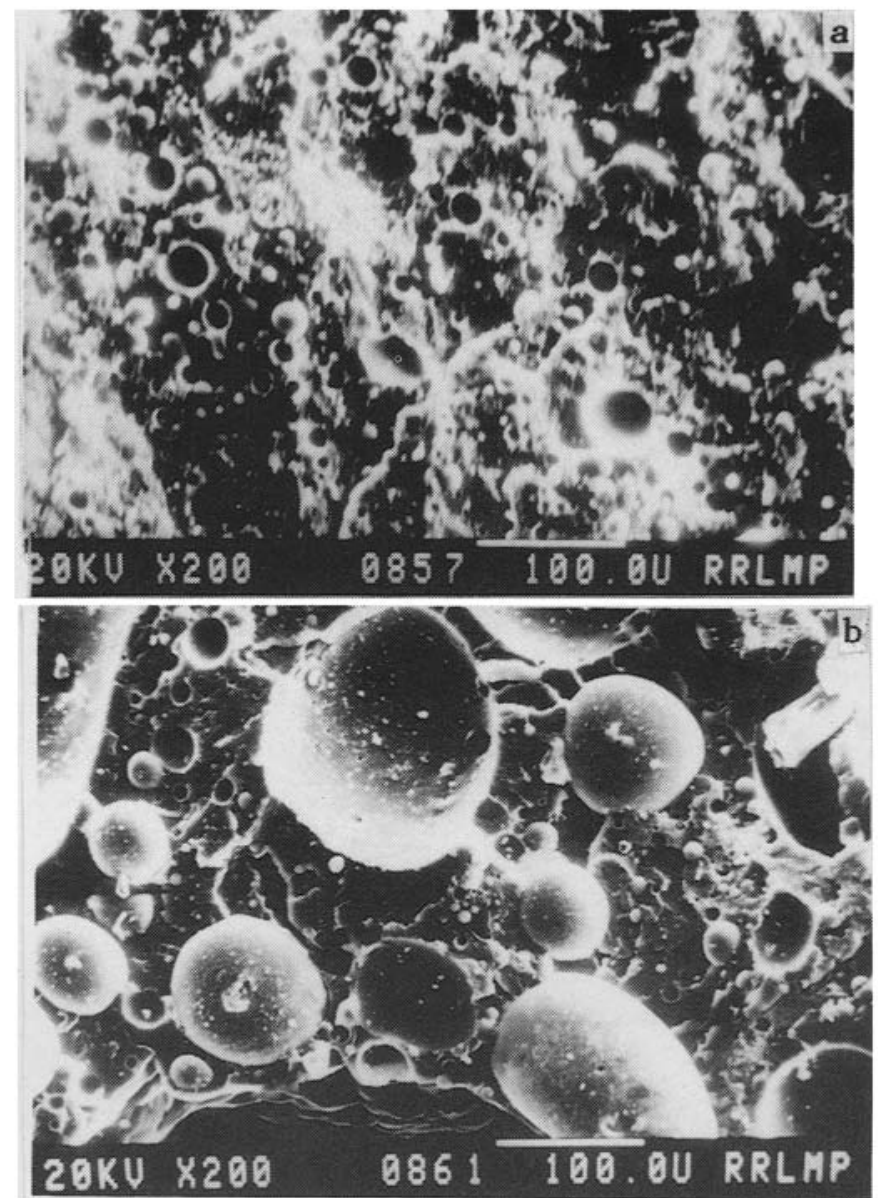

Figure 4. Cryogenically fractured surfaces of PP/PC/RM of compositions 80/20/5.26 (a) and 60/40/5.26 (b).

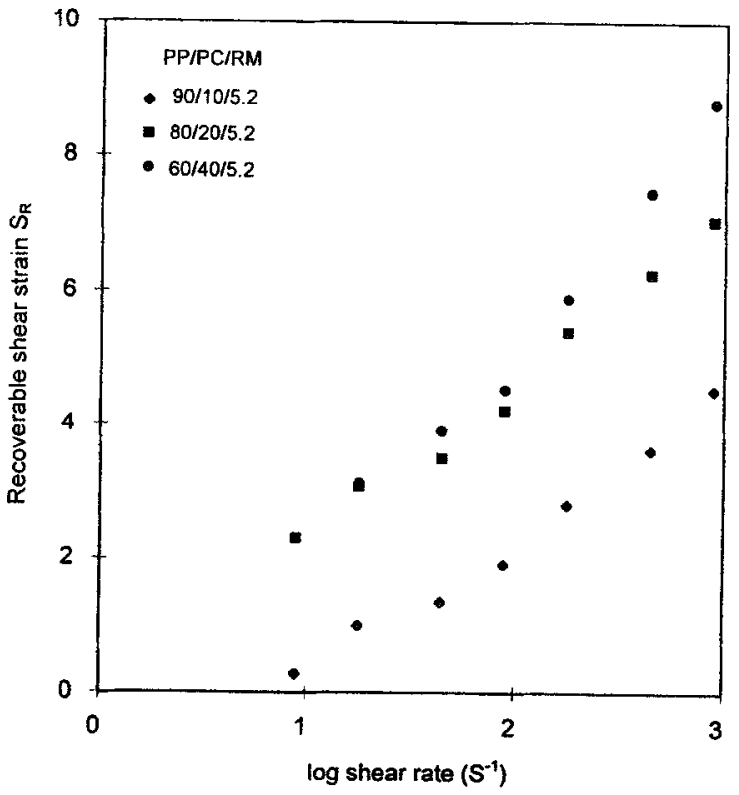

Figure 5. Shear strain recovery as a function of shear rate at $5.2 \mathrm{phr}$ loading of RM particles. 
$100 \mu \mathrm{m}$. Morphology of PP/PC blend provides evidence about their immiscibility.

Recoverable shear strain $\left(S_{\mathrm{R}}\right)$ vs shear rate is shown in figure 5. $S_{\mathrm{R}}$ increases with the shear rate as well as PC content in the blend. It can thus be inferred that $S_{\mathrm{R}}$ depends on elastic recovery of dispersed PC droplets. As discussed earlier the increased melt elasticity with PC content in the blend compensate for the decrease of melt viscosity.

\section{Conclusions}

Addition of polycarbonate improved thermal stability of red mud-filled polypropylene. However, the addition of polycarbonate reduced the shear stresses and hence the melt viscosity of red mud-filled polypropylene. Furthermore, recoverable shear strain increased with polycarbonate in red mud-filled polypropylene.

\section{References}

Bartlett D W, Paul D R and Barlow J W 1981 Mod. Plast. 5860

Chand N and Hashmi S A R 1995 Res. \& Ind. 40 124, 193

Chand N, Hashmi S A R and Vashishtha S R 1996 Indian J. Eng. \& Mater. Sci. 3253

Dobresu V and Cobzaru V 1978 J. Polym. Sci. Symp. 6427

Gleissle W 1982 Rheol. Acta 21485

Han C D 1976 Rheology in polymer processing (New York: Academic Press) Ch. 5

Hashmi S A R and Chand N 1996 J. Mater. Sci. Lett. 151343

Kitano T, Kakaoka T, Nishimura N and Sakai T 1980 Rheol. Acta 19764

Lepez O, Choplin L and Tanguy P A 1990 Polym. Engg. Sci. 30 821

Liang Z and Williams H L 1991 J. Appl. Polym. Sci. 43379

Nielsen L E 1974 in Mechanical properties of polymers and composites (New York: Marcell Dekker) Vols. 1 \& 2

Suetsuga Y 1982 SPEANTEC Tech. Papers 40598

Tanaka H and White J L 1980 Polym. Engg. Sci. 2949

Utracki L A 1984 Polym. Plast. Technol. Eng. 2227

Xavier S F, Schultz J and Friedrich K 1990 J. Mater. Sci. 252411 